\title{
AOHE: manuscript AOHE-D-16-00564 paroxysmal nocturnal hemoglobinuria with autoimmune hemolytic anemia following eculizumab therapy—with large granular lymphocytic leukemia
}

\author{
Nathan Visweshwar ${ }^{1}$ (D) - Michael Jaglal ${ }^{2}$ - Cassie Booth ${ }^{3}$ - Patrick Griffin ${ }^{2}$. \\ Damian Laber ${ }^{2}$
}

Received: 29 May 2016 / Accepted: 30 June 2016 / Published online: 23 July 2016

(C) The Author(s) 2016. This article is published with open access at Springerlink.com

Dear Editor,

A 49-year-old Turkish male presented with intermittent passage of dark-colored urine since 2007. Flow cytometry demonstrated absence of CD55 and CD59 antigens, consistent with a diagnosis of paroxysmal nocturnal hemoglobinuria (PNH). He initially responded to eculizumab, with improvement in anemia and resolution of hemoglobinuria. In 2009, the patient developed Coombs positive autoimmune hemolytic anemia (AIHA), which responded to steroids. Since he continued to require high doses of prednisone, splenectomy was performed in November 2009. Unfortunately, his AIHA persisted and he was treated with four weekly doses of rituximab $375 \mathrm{mg} / \mathrm{m}^{2}$ in June 2010. At that time, fluorescently labeled aerolysin (FLAER) labeling on leukocytes failed to demonstrate

Nathan Visweshwar

nviswesh@health.usf.edu

Michael Jaglal

Michael.jaglal@moffitt.org

Cassie Booth

cassiebooth@gmail.com

Patrick Griffin

Patrick.griffin@moffitt.org

Damian Laber

Damian.laber@moffitt.org

1 Department of Hematology, University of South Florida, 13330 USF Laurel Drive Tampa, Tampa, FL 33612, USA

2 Moffitt Cancer Center, Tampa, FL, USA

3 Tampa General Hospital, Tampa, FL, USA
PNH, so treatment with eculizumab was discontinued. In April 2014, the patient presented with septic shock in the setting of asplenia. He developed acral ischemic necrosis, requiring amputation of multiple fingers as well as his left leg below the knee. With appropriate resuscitation and antibiotic therapy, he was able to recover and he eventually regained independence with the aid of prosthesis. In February 2016, his complete blood count showed white blood cells $15,170 / \mathrm{mcL}$, with $66 \%$ lymphocytes, hemoglobin $9.2 \mathrm{~g} / \mathrm{dl}$, and platelets $510,000 / \mathrm{mcL}$. His peripheral blood smear revealed a predominance of large granular lymphocytes (LGL), which were CD8 and CD57 positive by flow cytometry (Figs. 1 and 2). Additional studies revealed clonal rearrangement of both beta and gamma $\mathrm{T}$ cell receptor genes, as well as a $\mathrm{CD} 4: \mathrm{CD} 8$ ratio of 0.1 . He continues to require prednisone for AIHA.

Paroxysmal nocturnal hemoglobinuria $(\mathrm{PNH})$ is an acquired clonal disorder caused by somatic mutation of the X-linked gene, PIG-A, which results in the deficiency of glycosylphosphatidylinositol (GPI) [1]. Deficiency of specific GPI anchored proteins, CD55 and CD59, renders red cells exquisitely sensitive to complement mediated destruction, leading to unabated intravascular hemolysis [2]. Complement blockade through the anti-C5 antibody, eculizumab, initially prevents hemolysis. However, over a period of time, a large number of $\mathrm{C} 3$ antigens accumulate [3]. $\mathrm{C} 3$ rich red cells with abnormal GPI molecules sensitize the immune system, resulting in $\mathrm{T}$ cell recognition and opsonization by macrophages of the reticuloendothelial system [4]. This phenomenon results in extravascular hemolysis with Coombs positivity in $\mathrm{PNH}$ patients on eculizumab [5]. Recent reports indicate that GPIspecific CD8 $+\mathrm{T}$ cells, which have been identified in 


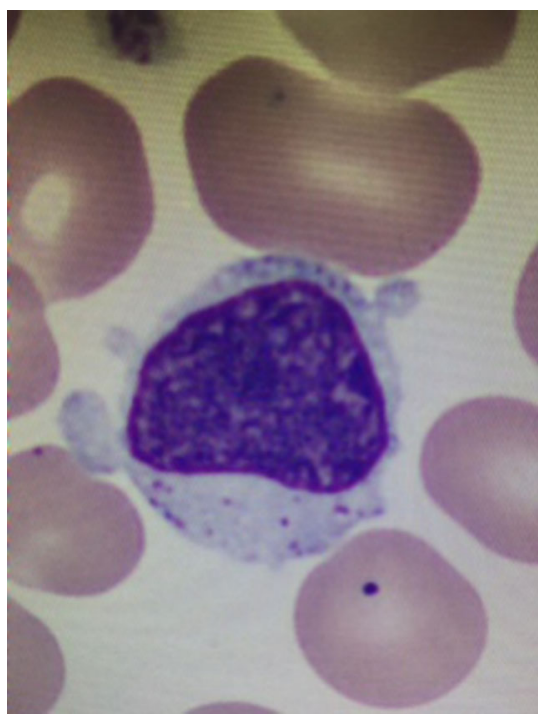

Fig. 1 Peripheral blood smear showing a large granular lymphocyte and a Howell-Jolly body (status post splenectomy)
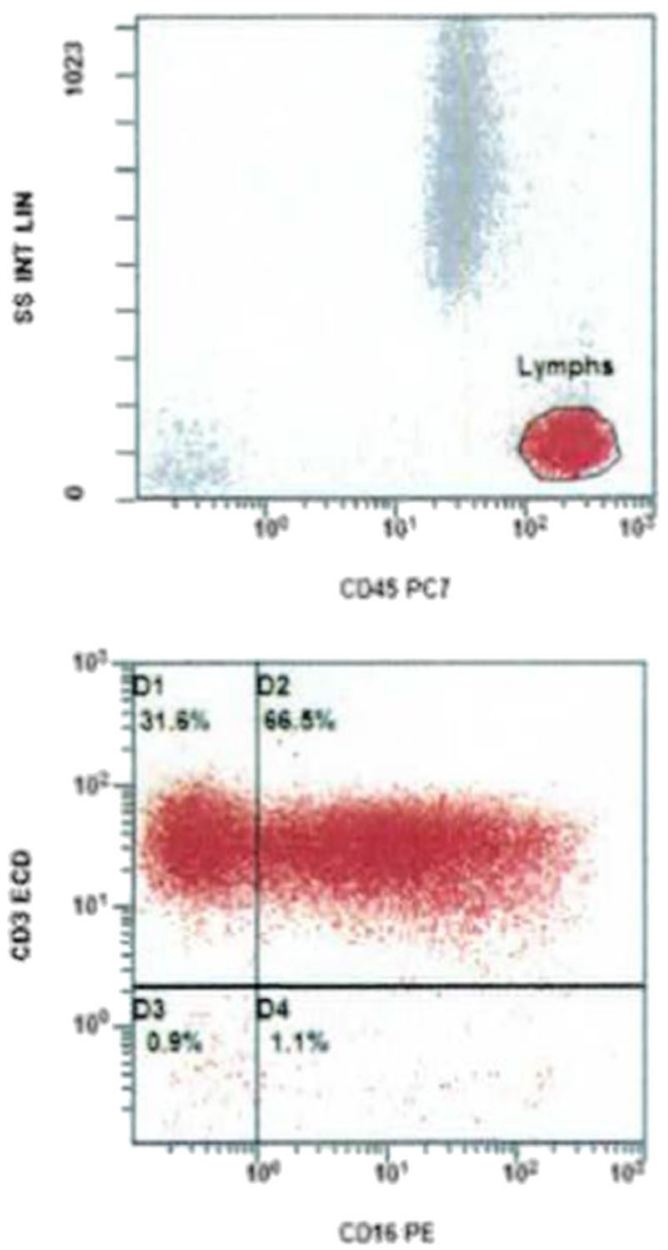

PNH patients, spare selectively GPI-negative stem cells, thus enabling them to re-populate the marrow of a patient who would otherwise have aplastic anemia [6]. T cell receptor beta (TCR-beta) clones of the $\mathrm{CD} 8+\mathrm{CD} 57+\mathrm{T}$ cell population are frequently deranged in $\mathrm{PNH}$, but not in healthy controls [7]. T cell clones bearing a set of highly homologous TCR-beta molecules in PNH suggest an immune process driven by non-peptide antigen, as patients do not share identical HLA alleles. In PNH patients, the presence of CD8 (+) $\mathrm{T}$ cells reactive against antigen-presenting cells (APCs) loaded with GPI are seen in higher numbers than in healthy controls [8]. To our knowledge, this is the first documented case of PNH with clonally mutated large granular lymphocytic leukemia with beta and gamma gene rearrangement, reported in the literature.

\section{[Lymphs] FLI imt LOGFL IIT LOG}

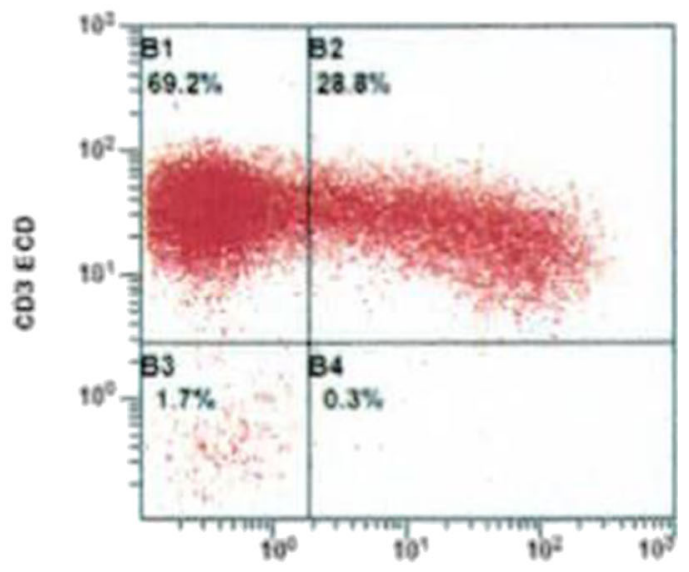

Cos? FITC

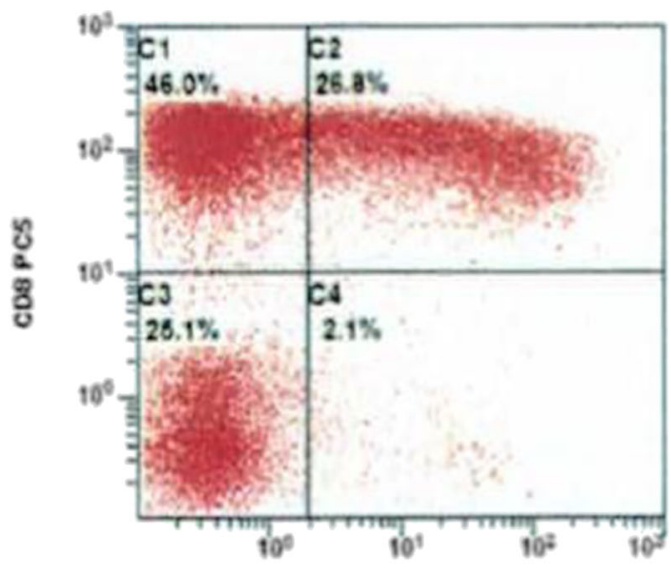

COS7 FITC

Fig. 2 Flow cytometry demonstrating a lymphocyte population with expression of both CD8 and CD57 


\section{Compliance with ethical standards}

Conflict of interest The authors declare that they have no conflict of interest.

Open Access This article is distributed under the terms of the Creative Commons Attribution 4.0 International License (http:// creativecommons.org/licenses/by/4.0/), which permits unrestricted use, distribution, and reproduction in any medium, provided you give appropriate credit to the original author(s) and the source, provide a link to the Creative Commons license, and indicate if changes were made.

\section{References}

1. Yamada $\mathrm{N}$ et al (1995) Somatic mutations of the PIG-A gene found in Japanese patients with paroxysmal nocturnal hemoglobinuria. Blood 85(4):885-892

2. Navenot JM et al (1993) Rapid diagnosis of paroxysmal nocturnal hemoglobinuria by gel test agglutination. Rev Fr Transfus Hemobiol 36(2):135-147
3. Nakayama H et al (2016) Eculizumab dosing intervals longer than 17 days may be associated with greater risk of breakthrough hemolysis in patients with paroxysmal nocturnal hemoglobinuria. Biol Pharm Bull 39(2):285-288

4. Risitano AM et al (2009) Complement fraction 3 binding on erythrocytes as additional mechanism of disease in paroxysmal nocturnal hemoglobinuria patients treated by eculizumab. Blood 113(17): 4094-4100

5. Hochsmann B et al (2012) Paroxysmal nocturnal haemoglobinuria treatment with eculizumab is associated with a positive direct antiglobulin test. Vox Sang 102(2):159-166

6. Luzzatto L (2016) Recent advances in the pathogenesis and treatment of paroxysmal nocturnal hemoglobinuria. F1000Res p 5. doi:10.12688/f1000research.7288.1

7. Gargiulo L et al (2007) Highly homologous T-cell receptor beta sequences support a common target for autoreactive T cells in most patients with paroxysmal nocturnal hemoglobinuria. Blood 109(11): 5036-5042

8. Gargiulo L et al (2013) Glycosylphosphatidylinositol-specific, CD1d-restricted T cells in paroxysmal nocturnal hemoglobinuria. Blood 121(14):2753-2761 